\title{
Studies on a novel mechanisms of VCP-mediated metastasis of osteosarcoma based on cell autophagy and EMT pathway
}

an an li ( $2460627147 @ q q . c o m$ )

First Affiliated Hospital of Nanchang University

\section{Yu Zhang}

First Affiliated Hospital of Nanchang University

fan li

Vocational College

yang zhou

First Affiliated Hospital of Nanchang University

zhi li liu

First Affiliated Hospital of Nanchang University

xin hua long

First Affiliated Hospital of Nanchang University

\section{Research Article}

Keywords: osteosarcoma, metastasis, Valosin-Containing Protein (VCP), Epithelial-Mesenchymal Transition (EMT), Autophagy

Posted Date: January 28th, 2022

DOl: https://doi.org/10.21203/rs.3.rs-957546/v1

License: (9) This work is licensed under a Creative Commons Attribution 4.0 International License. Read Full License 


\section{Abstract}

Objective: Study of the molecular mechanisms of metastasis is still the research focus for osteosarcoma(OS) prevention. This study is to explore a new way for VCP promoting OS metastasis from the perspective of autophagy and epithelial-mesenchymal transition (EMT) in vitro.

Method: Different cell lines of osteosarcoma (143B and MG63) were adopted in this study. Gene interference technology was used to down-regulate the expression of VCP, and the expression levels of autophagy and EMT-related protein in OS cells were detect by western blot, as well as smad pathway related protein. Then the process of autophagy and EMT in OS cells were changed artificially, and the cells phenotype were detected respectively.

Result: The expression of the LC3II/I was decreased but the insolubilized P62 protein expression was increased in VCP inhibiting group, as well as that in autophagy inhibitor treatment group, which suggesting the down-regulation of the autophagy level of OS cells. At the same time, the expression of the E-cadherin protein was incresed but the $\mathrm{N}$-cadherin was decreased which suggesting the downregulation of the EMT level in VCP inhibiting group, contrarily that in TGF- $\beta 1$ treatment group. In addition, suppressing VCP can cause a decrease of Transforming Growth Factor $\beta 1 \otimes T G F-\beta 1 \bigotimes$, smad2, smad3,

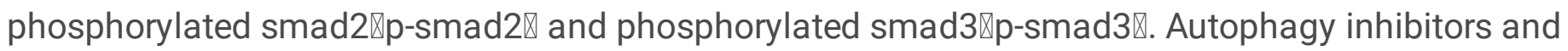
agonists has no significant effect on the migration and invasion of OS cells, but can significantly affect the ability of cells to resist anoikis. EMT inhibitors and agonists has a proportional effect on the migration and invasion of OS cells.

Conclusion: VCP is likely to promote the migration and invasion of OS cells by inducing EMT possibly via TGF- $\beta 1 /$ Smad2/3 signaling pathway, and VCP-mediated autophagy plays a key role in this process, contributing to the successful distant metastasis of tumor cells.

\section{Introduction}

Osteosarcoma (OS) is one of the most common malignant bone tumors that usually occurs in children adolescents, with an incidence of about 2 to 3 parts per million/year[1]. It is prone to metastasis, and the 5 -year survival rate of patients with metastasis is less than $20 \%$ [2-4].The lung is the most common metastatic site for OS, and pulmonary metastasis is the main cause of death in patients[5, 6]. But, there is no better strategy for OS metastasis so far. Therefore, it is essential to explore the mechanism of OS metastasis.

Valosin-containing protein (VCP), also known as P97, belongs to the AAA+ protein family[7, 8]. As a multifunctional protein, it participates in many cell biological processes, including protein degradation, membrane fusion, apoptosis, transcription activation and autophagy[9-13]. Studies have shown that VCP was over-expressed in many tumors and was associated with the occurrence, development and poor prognosis, including non-small cell lung cancer[14], colorectal cancer[15], prostate cancer[16], esophageal carcinomas[17], and breast cancer[18]. In previous studies, VCP was proved to be highly expressed and 
related to the metastasis of osteosarcoma. Through further mechanism exploration, it was revealed that VCP was involved in the invasion and migration of OS cells, inpart through the activation of the PI3K/Akt signaling pathway[19] .And it also showed that VCP can enhance the autophagy level and ability to resist anoikis in osteosarcoma cells, However, changing the autophagy level has no obvious effect on the invasion phenotype of osteosarcoma. Therefore, we speculate that VCP-mediated metastasis of osteosarcoma may also involve other pathways, in which, autophagy may played an important.

Many studies have confirmed that epithelial to mesenchymal transition (EMT) is a key step in tumor progression and metastasis [20-23]. EMT is manifested by the gradual disappearance of the characteristics of epithelial cells, the adhesion between cells is further reduced, and the ability to degrade the extracellular matrix is obtained, which is a key step in the mechanism of tumor invasion and metastasis. Other studies also reported that TGF- $\beta$ can promote tumor metastasis by inducing EMT[2426]. Although osteosarcoma is derived from mesenchymal cells, a large number of recent studies[27-29] have found that EMT also plays a key role in the metastasis of osteosarcoma. Whether EMT process involved in VCP-mediated metastasis of osteosarcoma is remained unknown.

This study is to explore a new mechanism of autophagy and EMT involved in VCP-mediated osteosarcoma metastasis based on our previous research.

\section{Materials And Methods}

\section{Cell culture}

Human osteosarcoma cell lines 143B and MG63 were purchased from the Cell Bank of the Chinese Academy of Sciences in Shanghai, China. 143B cells were cultured in MEM Alpha Modification Medium (a-MEM, Gibco. Thermo Fisher Scientific) and MG63 cells were cultured in Minimum Essential Medium(MEM, Gibco) containing 10\% Fetal Bovine Serum (Gibco), both supplemented with $100 \mathrm{U} / \mathrm{ml}$ penicillin and $100 \mathrm{U} / \mathrm{ml}$ streptomycin. The cell culture environment was unified as at $37^{\circ} \mathrm{C}$ incubator containing $5 \%$ carbon dioxide.

\section{Cell transfection}

The reverse complement sequence were cloned into the lentivirus vector GV159 to construct an siRNA vector that down-regulates VCP. The sequence of siRNA is as follows: VCP siRNA (si) sense, R: $5^{\prime} \rightarrow 3^{\prime}$ CCTGTACAGGTCATCCATTGTCTGTCAGTCAGTGGCCAAAACAG ACAATGATGATGACCTGTAC;F :TGCTGTACAGGTCATCATCATTGTCTGTTTTGGCCACTGACTGACAGACAATGGATGACCTGTA; Similarly, in order to construct a negative control group, clone the non-functional negative sequence into the viral vector. si-negative control (siCON) sense, R: $5^{\prime} \rightarrow 3^{\prime}$

CCTGAAATGTACTGCGTGGAGACGTCAGTCAGTGGCCAA AACGTCTCCACGCGCAGTACATTTC; F:5-3' TGCTGAAATGTACTGCGCGTG GAGACGTTTTGGCCACTGACTGACGTCTCCACGCAGTACA TTT. Then a viral vector that down-regulates the VCP was used to transfect the cells, and the virus was removed 14 hours later. After continuing the culture for 48 hours, the cells were treated with puromycin for 24 hours to 
screen for puromycin-resistant cells, and then the cells were plated and planted for subsequent experiments. (Invitrogen; Thermo Fisher Scientific).

\section{Reverse transcription-polymerase chain reaction( RT-PCR)}

Total RNA was extracted using Trizol(Invitrogen, USA) reagent on ice plate, then reverse transcribed into stable cDNA. Bio-Rad CFX 96 Touch real-Time PCR detection system (cat. no. 1855196, Bio-rad laboratories, inc.) were used for RT-PCR. The thermocycling conditions were as follows: $95^{\circ} \mathrm{C}$ for $5 \mathrm{~min}, 40$ cycles of $95^{\circ} \mathrm{C}$ for $15 \mathrm{sec}, 60^{\circ} \mathrm{C}$ for $30 \mathrm{sec}$ and $70^{\circ} \mathrm{C}$ for $10 \mathrm{sec}$. GAPDH was used as a reference object, and its mRNA primer sequence is ( $R: 5^{\prime} \rightarrow 3^{\prime}$ AGCCTTCTCCATGGTGGTGAAGAC; $F$ $: 5^{\prime} \rightarrow 3^{\prime}$ CGGAGTCAACGGATTTGGTCGTAT). The primer sequence of VCP mRNA is as follows: R: $5^{\prime} \rightarrow 3^{\prime}$ AAACCGTGGTAGAGGTGCCA ; $F: 5^{\prime} \rightarrow 3^{\prime}$ CTTGGAAGGTGTCATGCCAA. Relative expression was calculated using the2- $\triangle \Delta$ Ctmethod. $A$ total of 6 independent experiments were performed.

\section{Western Blotting (WB)}

Total protein of cells was extracted with RIPA (Beyotime, china) lysis buffer, and the protein concentration was measured with BCA (Boster, china) kit. Protein was separated with SDS-polyacrylamide gel (Bio-rad, USA) and transferd to NC membrane. Blocked with 5\% skim milk at room temperature for 1 hour.Western blot analysis was conducted using primary antibodies against VCP (cat. no. ab36047), beclin-1 (cat. no. ab210498), TGF- $\beta 1$ (cat. no. Ab215715), smad2 (cat. no. ab40855), smad2(phospho S467) (cat. no. Ab280888), smad3 (cat. no. ab40854), smad3(phospho T179) (cat. no. Ab74062), E-cadherin (cat. no. ab40772), N-cadherin (cat. no. ab76011) and LC3 (cat.no. ab128025; all Abcam; dilution, 1:2,000) and GAPDH (cat.no. sc-48166, Santa Cruz Biotechnology, Inc.; dilution, 1:5,000)and horseradish peroxidase-conjugated secondary antibodies(cat. nos. sc-2004 and sc-2020, Santa Cruz Biotechnology, Inc.; dilution, 1:5,000). Membranes were incubated with primaryantibodies at $4^{\circ} \mathrm{C}$ for $\sim 12 \mathrm{~h}$ (overnight), and subsequently with secondary antibodies at room temperature for 2-3 h. Immune complexes were detected using a pro-light HRP kit (Pierce;Thermo Fisher Scientific, Inc.). The strip gray value was determined using ImageJ software (version 1.46; National Institutes of Health). A total of 6 independent experiments were performed.

\section{MTT assay}

Osteosarcoma MG63 and 143B cells $\left(2 \times 10^{6}\right.$ cells) were cultured in suspension for 7 days and then cultured in adherent for $6 \mathrm{~h}$. MTT solution $(5 \mathrm{mg} / \mathrm{ml} ; 500 \mu \mathrm{l} /$ well) was added to a 24-well plate, incubated for $4 \mathrm{~h}$ at $37^{\circ} \mathrm{C}, 1 \mathrm{ml} \mathrm{DMSO}$ was added to each well, and the plate was agitated for $10 \mathrm{~min}$ to completely dissolve the crystals. The absorbance at $490 \mathrm{~nm}$ was measured using a microplate spectrophotometer.

\section{Migration assay}

Cell migration was assessed using a wound healing assay to determine the ability of cells to move into a cellular space in two-dimensions, in vitro. In brief, cells were cultured to confluence in six-well tissue 
culture dishes, to a density of $\sim 5 \times 10^{6}$ cells/well. The wound was created by dragging a rubber policeman (Thermo Fisher Scientific, Inc.) across the center of the plate. Cultures were rinsed with PBS and replaced with fresh medium alone or containing $10 \mathrm{~g} / \mathrm{I}$ BSA (Gibco;Thermo Fisher Scientific, Inc.), and incubated at $37^{\circ} \mathrm{C}$ for $24 \mathrm{~h}$. BSA was only used in place of FBS in the wound healing experiments. Images were captured using a light microscope at 0 and $24 \mathrm{~h}$, and the migration distance was determined using ImageJ Software (National Institutes of Health).

\section{Transwell invasion assay}

The invasiveness of OS cells was assessed using the BD BioCoat ${ }^{\mathrm{TM}} \mathrm{BD}$ Matrige ${ }^{\mathrm{TM}}$ Invasion Chamber (BD Bioscience) according to the manufacturer's protocol. Cells $\left(2 \times 10^{5}\right)$ were resuspended in serum-free DMEM and added to the upper chambers; the medium in the lower chambers contained $5 \%$ FBS as a chemo-attractant. At $24 \mathrm{~h}$, cells that had migrated through the Matrigel-coated membrane were stained with Diff-Quik (Sysmex Corporation, Kobe) at room temperature in Diff-Quik A for 10-20 sec, Diff-Quik B for 5-10 sec and Diff-Quik C for 5-10 sec, and images were captured under a light microscope (magnification).

\section{Interference experiment}

3-methyladenine(3-MA) was used as autophagy inhibitor, and rapamycin as autophagy agonist. TGF- $\beta 1$ and SIS3 acted as inducers and inhibitors of EMT, respectively. For the cells subjected to RNA interference, drug treatment was performed $24 \mathrm{~h}$ after transfection.

\section{Statistical analysis}

All statistical analyses were conducted using SPSS software (version 19.0; SPSS Inc., Chicago, IL,USA). Data are expressed as the mean \pm standard deviation. One-way analysis of variance followed by a Fisher's Least Significant Difference test was used to analyze multiple samples. $\mathrm{P}<0.05$ was considered to indicate a statistically significant difference.

\section{Results}

\section{The expression of VCP in OS cells was downregulated via gene interference technology}

siRNA vector for the downregulation of VCP was used to transfect the two cells lines of osteosarcoma(143B and MG63). And then quantitive-polymerase Chain Reaction(qPCR) and Western Blot(WB) techniques were performed to detect the expression of VCP. The results showed that VCP-mRNA and protein expression were significantly down-regulated.(Figure 1).

\section{Down-regulation of VCP can inhibit autophagy in OS cells}

In order to explore the relationship between VCP and autophagy in OS cell lines 143B and MG63, autophagy-related proteins were detected while VCP expression was inhibited. Results showed that the 
expression level of LC3II/I in the VCP-inhibiting group was significantly down-regulated compared with the negative group, while P62 expression was up-regulated. At the same time, while treated with autophagy inhibitor, the expression level of LC3II/I in OS cells was significantly down-regulated but P62 was contrary. (figure.2). LC3II/I and P62 were displayed to be two important marker products in the process of autophagy. All of the above results suggested that down-regulation of VCP can inhibit autophagy.

\section{Down-regulation of VCP can inhibit EMT in OS cells}

To evaluable the relationship between VCP and EMT, the expression level of EMT-related protein , Ecadherin and N-cadherin, was detected by WB. Results showed that the expression level of N-cadherin in VCP-inhibiting group was significantly down-regulated compared with the negative group, while Ecadherin expression was up-regulated. At the same time, while treated with EMT agonist (TGF- $\beta 1$ ), the expression level of $\mathrm{N}$-cadherin in OS cells was significantly up-regulated but E-cadherin was contrary. $\mathrm{N}$ cadherin and E-cadherin were displayed to be two important marker products in the process of EMT. All results suggested that down-regulation of VCP can inhibit EMT.

\section{The effect of autophagy on the phenotype of OS cells.}

OS cells were treated with autophagy inhibitor and agonist, then cell migration and invasion ability were detected, as well as cell anti-anoikis ability after 7-days suspension culture. The results showed that the migration rate and trans-membrane cells in autophagy inhibitor treating group were not different from that in autophagy agonist treating group. However, after 7-days suspension culture, the survival cells in autophagy inhibitor treating group were significantly lower than that in autophagy agonist treating group. Results suggest that changing the level of autophagy cannot effect the migration and invasion ability of OS cells but anti-anoikis ability.

\section{The effect of EMT on the phenotype of OS cells}

OS cells were treated with EMT inhibitor and agonist, then cell migration and invasion ability were detected. The results showed that the migration rate and trans-membrane cells in EMT inhibitor treating group were significantly down-regulated, but that in EMT agonist treating group were up-regulated, compare to control group. Results revealed that EMT could induce migration and invasion of OS cells. EMT is probablely involved in VCP-mediated metastasis of OS.

\section{VCP may induce EMT via TGF- $\beta 1 / \mathrm{Smad} / 3$ signaling pathway}

In order to explore the likely mechanism of EMT induced by VCP, the expression of VCP in the two OS cell lines were inhibited by siRNA, and smad pathway related proteins were detected by WB.The results showed that compared with the negative group, the protein expression levels of TGF- $\beta 1$, smad2, p-smad2 and smad3, p-smad3 in the VCP inhibiting group were significantly reduced. (Figure 6) Results suggested that VCP may induce EMT via TGF- $\beta 1 /$ Smad2/3 signaling pathway. 


\section{Discussion}

Osteosarcoma metastasis is the bottleneck of its treatment, so continuous research on the mechanism of osteosarcoma metastasis has always been the focus.

VCP is reported to be involved in the development of various types of tumor (15-19). Previous studies have revealed that VCP expression level in OS tissue with pulmonary metastasis were higher than that without pulmonary metastatic disease. Inhibition of VCP expression may suppress OS metastasis by modulating the PI3K/NF-K $\beta$ signaling pathway (19). However, our previous study revealed that inhibition of the PI3K/NF-K $\beta$ pathway does not completely reverse VCP-mediated invasion and migration of OS (Long et al, unpublished data). The further study found that VCP could induces autophagy and inhibits anoikis to promote osteosarcoma metastasis[30]. But the level of autophagy has no effect on the invasion and metastasis ability of OS cells, which suggests that other mechanisms of VCP-mediated OS invasion and migration may be involved.

Epithelial to mesenchymal transition(EMT) is a carefully planned event in which polarized epithelial cells differentiate into more motile and migratory mesenchymal-like cells[31]. Decrease of epithelial markers (e.g. E-cadherin) and increase of mesenchymal markers (e.g. N-cadherin) are signs of EMT. Many studies have confirmed that the activation of EMT promotes the dissociation and invasion of tumor cells, provides a prerequisite for tumor cells to transfer to distant organs, and finally leads to the spread of cancer and treatment failure[20-23]. And the important role of autophagy in the occurrence, metastasis and drug resistance of tumors also has been confirmed by a large number of studies[32-36]. What the two processes of autophagy and epithelial to mesenchymal transition (EMT) are interacting in VCPmediated metastasis of osteosarcoma?

In this study, two osteosarcoma cell lines(143B and MG63)were used at the same time to further clarify the relationship between VCP expression and autophagy, as well as EMT. Gene interference technology was applied to inhibiting VCP expression in the two OS cell lines, and autophagy marker proteins(LC3II/I and P62) and EMT marker proteins(E-cadherin and N-cadherin) were detected separately. Results suggested that down-regulation of VCP can inhibit autophagy as well as EMT. In the following test, it was found that the use of autophagy inhibitors and agonists has no significant effect on the migration and invasion of Os cells, but can significantly affect the ability of cells to resist anoikis. The use of EMT inhibitors and agonists has a proportional effect on the migration and invasion of OS cells. Thus, we infer that the activation of EMT promotes the dissociation and invasion of tumor cells, provides a prerequisite for tumor cells to transfer to distant organs. In this process, autophagy could provide the cells leaving the matrix with the necessary energy for survival and the basic substances required for maintaining stability, so that the tumor cells will not die after leaving the primary tumor before the metastasis grows, and finally leads to the successful spread of cancer and treatment failure. But what is the possible mechanism of VCP-mediated EMT process?

Studies reported that TGF- $\beta$ signal transduction is one of the most important EMT inducers, which obviously promotes the development of cancer in the later stage of the tumor, leading to tumor cell 
migration and metastasis[24-26]. Other studies reported that the Transforming Growth Factor- $\beta 1 / S m a d$ signaling pathway plays a vital role in the occurrence of EMT[37-39]. In this study, we detected that the expression levels of TGF- $\beta 1$, smad2, smad3 and phosphorylated smad2 and phosphorylated smad3 were also significantly down-regulated when suppressing VCP expression. Therefore, we speculate that VCP may induce the occurrence of EMT through the TGF- $\beta 1 / \mathrm{Smad} 2 / 3$ signaling pathway, of which further research is needed to confirm.

\section{Conclusions}

In conclusion, in the present study, VCP could promote autophagy and EMT at the same time, and it is likely to promote the migration and invasion of OS cells by inducing EMT possibly via TGF- $\beta 1 / \mathrm{Smad} 2 / 3$ signaling pathway. At the meanwhile, autophagy plays a key role in the VCP-mediated EMT process, contributing to the successful distant metastasis of tumor cells. These findings will provide a basis for proposing novel treatment strategies for patients with OS.

\section{Declarations}

\section{Conflict of interest statement and consent for publication}

All authors have no conflict of interest and agree to be published in your journal

\section{Contribution}

The author (An-An Li) and author (Yu-Zhang) share first author of this study.

\section{Ethics Approval and consent to participate}

Our research was approved by the ethics committee and all personnel agreed to participate in the research

\section{Availability of data and materials}

All our raw data is reliable

\section{Acknowledgments}

Not applicable

\section{Funds}

This work was supported by the Project of Youth Science Foundation of Jiangxi Province(No. 20202BABL216048). 
And this work is also supported by the Postgraduate Innovation Special Fund Project of Jiangxi Province, China(No.YC2021-B051).

\section{References}

1. Ritter J, Bielack SS. Osteosarcoma. Ann Oncol. 2010 Oct;21 Suppl 7:vii320-5. doi: 10.1093/annonc/mdq276. PMID: 20943636.

2. Mialou V, Philip T, Kalifa C, Perol D, Gentet JC, Marec-Berard P, Pacquement H, Chastagner P, Defaschelles AS, Hartmann O. Metastatic osteosarcoma at diagnosis: prognostic factors and longterm outcome-the French pediatric experience. Cancer. 2005 Sep 1;104(5):1100-9. doi: 10.1002/cncr.21263. PMID: 16015627.

3. Niswander LM, Kim SY. Stratifying osteosarcoma: minimizing and maximizing therapy. Curr Oncol Rep. 2010 Jul;12(4):266-70. doi: 10.1007/s11912-010-0106-3. PMID: 20473649; PMCID: PMC7316378.

4. Cersosimo F, Lonardi S, Bernardini G, Telfer B, Mandelli GE, Santucci A, Vermi W, Giurisato E. TumorAssociated Macrophages in Osteosarcoma: From Mechanisms to Therapy. Int J Mol Sci. $2020 \mathrm{Jul}$ 23;21(15):5207. doi: 10.3390/ijms21155207. PMID: 32717819; PMCID: PMC7432207.

5. Ando K, Heymann MF, Stresing V, Mori K, Rédini F, Heymann D. Current therapeutic strategies and novel approaches in osteosarcoma. Cancers (Basel). 2013 May 24;5(2):591-616. doi: 10.3390/cancers5020591. PMID: 24216993; PMCID: PMC3730336.

6. Koshkina N, Yang Y, Kleinerman ES. The Fas/FasL Signaling Pathway: Its Role in the Metastatic Process and as a Target for Treating Osteosarcoma Lung Metastases. Adv Exp Med Biol. 2020;1258:177-187. doi: 10.1007/978-3-030-43085-6_12. PMID: 32767242.

7. Ewens CA, Kloppsteck P, Förster A, Zhang X, Freemont PS. Structural and functional implications of phosphorylation and acetylation in the regulation of the AAA+ protein p97. Biochem Cell Biol. 2010 Feb;88(1):41-8. doi: 10.1139/o09-128. PMID: 20130678.

8. van den Boom J, Meyer H. VCP/p97-Mediated Unfolding as a Principle in Protein Homeostasis and Signaling. Mol Cell. 2018 Jan 18;69(2):182-194. doi: 10.1016/j.molcel.2017.10.028. Epub 2017 Nov 16. PMID: 29153394.

9. Suvarna $\mathrm{K}$, Honda $\mathrm{K}$, Muroi M, Kondoh $\mathrm{Y}$, Osada H, Watanabe N. A small-molecule ligand of valosincontaining protein/p97 inhibits cancer cell-accelerated fibroblast migration. J Biol Chem. $2019 \mathrm{Mar}$ 1;294(9):2988-2996. doi: 10.1074/jbc.RA118.004741. Epub 2019 Jan 4. PMID: 30610116; PMCID: PMC6398144.

10. Meyer $\mathrm{H}$, Weihl CC. The VCP/p97 system at a glance: connecting cellular function to disease pathogenesis. J Cell Sci. 2014 Sep 15;127(Pt 18):3877-83. doi: 10.1242/jcs.093831. Epub 2014 Aug 21. PMID: 25146396; PMCID: PMC4163641.

11. Mengus C, Neutzner M, Bento ACPF, Bippes CC, Kohler C, Decembrini S, Häusel J, Hemion C, Sironi L, Frank S, Scholl HPN, Neutzner A. VCP/p97 cofactor UBXN1/SAKS1 regulates mitophagy by 
modulating MFN2 removal from mitochondria. Autophagy. 2021 May 9:1-20. doi:

10.1080/15548627.2021.1922982. Epub ahead of print. PMID: 33966597.

12. Stach L, Freemont PS. The AAA+ ATPase p97, a cellular multitool. Biochem J. 2017 Aug 17;474(17):2953-2976. doi: 10.1042/BCJ20160783. PMID: $28819009 ;$ PMCID: PMC5559722.

13. Huryn DM, Kornfilt DJP, Wipf P. p97: An Emerging Target for Cancer, Neurodegenerative Diseases, and Viral Infections. J Med Chem. 2020 Mar 12;63(5):1892-1907. doi: 10.1021/acs.jmedchem.9b01318. Epub 2019 Oct 9. PMID: 31550150.

14. Wang Y, Zhang J, Li YJ, Yu NN, Liu WT, Liang JZ, Xu WW, Sun ZH, Li B, He QY. MEST promotes lung cancer invasion and metastasis by interacting with VCP to activate NF-kB signaling. J Exp Clin Cancer Res. 2021 Sep 24;40(1):301. doi: 10.1186/s13046-021-02107-1. PMID: 34560900; PMCID: PMC8464132.

15. Fu Q, Jiang Y, Zhang D, Liu X, Guo J, Zhao J. Valosin-containing protein (VCP) promotes the growth, invasion, and metastasis of colorectal cancer through activation of STAT3 signaling. Mol Cell Biochem. 2016 Jul;418(1-2):189-98. doi: 10.1007/s11010-016-2746-6. Epub 2016 Jun 25. PMID: $27344168 ;$ PMCID: PMC4927615.

16. Duscharla D, Reddy Kami Reddy K, Dasari C, Bhukya S, Ummanni R. Interleukin-6 induced overexpression of valosin-containing protein (VCP)/p97 is associated with androgen-independent prostate cancer (AIPC) progression. J Cell Physiol. 2018 Oct;233(10):7148-7164. doi:

10.1002/jcp.26639. Epub 2018 Apr 25. PMID: 29693262.

17. Luo H, Song H, Mao R, Gao Q, Feng Z, Wang N, Song S, Jiao R, Ni P, Ge H. Targeting valosincontaining protein enhances the efficacy of radiation therapy in esophageal squamous cell carcinoma. Cancer Sci. 2019 Nov;110(11):3464-3475. doi: 10.1111/cas.14184. Epub 2019 Sep 13. PMID: 31454136; PMCID: PMC6825005.

18. Zhu C, Rogers A, Asleh K, Won J, Gao D, Leung S, Li S, Vij KR, Zhu J, Held JM, You Z, Nielsen TO, Shao J. Phospho-Ser784-VCP Is Required for DNA Damage Response and Is Associated with Poor Prognosis of Chemotherapy-Treated Breast Cancer. Cell Rep. 2020 Jun 9;31(10):107745. doi: 10.1016/j.celrep.2020.107745. PMID: 32521270; PMCID: PMC7282751.

19. Long XH, Zhang ZH, Liu ZL, Huang SH, Luo QF. Inhibiting valosin-containing protein suppresses osteosarcoma cell metastasis via AKT/nuclear factor of kappa B signaling pathway in vitro. Indian J Pathol Microbiol. 2013 Jul-Sep;56(3):190-5. doi: 10.4103/0377-4929.120358. PMID: 24152492.

20. Lu W, Kang Y. Epithelial-Mesenchymal Plasticity in Cancer Progression and Metastasis. Dev Cell. 2019 May 6;49(3):361-374. doi: 10.1016/j.devcel.2019.04.010. PMID: 31063755; PMCID: PMC6506183.

21. Zhang Y, Weinberg RA. Epithelial-to-mesenchymal transition in cancer: complexity and opportunities. Front Med. 2018 Aug;12(4):361-373. doi: 10.1007/s11684-018-0656-6. Epub 2018 Jul 24. PMID: 30043221; PMCID: PMC6186394.

22. Dongre A, Weinberg RA. New insights into the mechanisms of epithelial-mesenchymal transition and implications for cancer. Nat Rev Mol Cell Biol. 2019 Feb;20(2):69-84. doi: 10.1038/s41580-018-0080- 
4. PMID: 30459476.

23. Mittal V. Epithelial Mesenchymal Transition in Tumor Metastasis. Annu Rev Pathol. 2018 Jan 24;13:395-412. doi: 10.1146/annurev-pathol-020117-043854. PMID: 29414248.

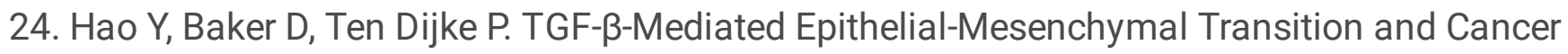
Metastasis. Int J Mol Sci. 2019 Jun 5;20(11):2767. doi: 10.3390/ijms20112767. PMID: 31195692; PMCID: PMC6600375.

25. Yoshimatsu Y, Wakabayashi I, Kimuro S, Takahashi N, Takahashi K, Kobayashi M, Maishi N, PodymaInoue KA, Hida K, Miyazono K, Watabe T. TNF-a enhances TGF- $\beta$-induced endothelial-tomesenchymal transition via TGF- $\beta$ signal augmentation. Cancer Sci. 2020 Jul;111(7):2385-2399. doi: 10.1111/cas.14455. Epub 2020 Jun 11. PMID: 32385953; PMCID: PMC7385392.

26. Yu Y, Luo W, Yang ZJ, Chi JR, Li YR, Ding Y, Ge J, Wang X, Cao XC. miR-190 suppresses breast cancer metastasis by regulation of TGF- $\beta$-induced epithelial-mesenchymal transition. Mol Cancer. 2018 Mar 6;17(1):70. doi: 10.1186/s12943-018-0818-9. PMID: 29510731; PMCID: PMC5838994.

27. Mao X, Jin Y, Feng T, Wang H, Liu D, Zhou Z, Yan Q, Yang H, Yang J, Yang J, Ye Y, Su Y, Zuo G. Ginsenoside Rg3 Inhibits the Growth of Osteosarcoma and Attenuates Metastasis through the Wnt/ $\beta$-Catenin and EMT Signaling Pathway. Evid Based Complement Alternat Med. 2020 Jul 11;2020:6065124. doi: 10.1155/2020/6065124. PMID: 32733585; PMCID: PMC7369650.

28. Peng YX, Yu B, Qin H, Xue L, Liang YJ, Quan ZX. EMT-related gene expression is positively correlated with immunity and may be derived from stromal cells in osteosarcoma. PeerJ. 2020 Feb 3;8:e8489. doi: 10.7717/peerj.8489. PMID: 32117617; PMCID: PMC7003688.

29. Xie C, Liu S, Wu B, Zhao Y, Chen B, Guo J, Qiu S, Cao YM. miR-19 Promotes Cell Proliferation, Invasion, Migration, and EMT by Inhibiting SPRED2-mediated Autophagy in Osteosarcoma Cells. Cell Transplant. 2020 Jan-Dec;29:963689720962460. doi: 10.1177/0963689720962460. PMID: 33023313; PMCID: PMC7784565.

30. Long XH, Zhou YF, Lan M, Huang SH, Li Liu Z, Shu Y. Valosin-containing protein promotes metastasis of osteosarcoma through autophagy induction and anoikis inhibition via the ERK/NF-к $\beta /$ beclin-1 signaling pathway. Oncol Lett. 2019 Oct;18(4):3823-3829. doi: 10.3892/ol.2019.10716. Epub 2019 Aug 6. PMID: 31516594; PMCID: PMC6732942.

31. Lamouille S, Xu J, Derynck R. Molecular mechanisms of epithelial-mesenchymal transition. Nat Rev Mol Cell Biol. 2014 Mar;15(3):178-96. doi: 10.1038/nrm3758. PMID: 24556840; PMCID: PMC4240281.

32. Onorati AV, Dyczynski M, Ojha R, Amaravadi RK. Targeting autophagy in cancer. Cancer. 2018 Aug;124(16):3307-3318. doi: 10.1002/cncr.31335. Epub 2018 Apr 19. PMID: 29671878; PMCID: PMC6108917.

33. Parzych KR, Klionsky DJ. An overview of autophagy: morphology, mechanism, and regulation. Antioxid Redox Signal. 2014 Jan 20;20(3):460-73. doi: 10.1089/ars.2013.5371. Epub 2013 Aug 2. PMID: 23725295; PMCID: PMC3894687. 
34. Kocaturk NM, Akkoc Y, Kig C, Bayraktar O, Gozuacik D, Kutlu O. Autophagy as a molecular target for cancer treatment. Eur J Pharm Sci. 2019 Jun 15;134:116-137. doi: 10.1016/j.ejps.2019.04.011. Epub 2019 Apr 11. PMID: 30981885.

35. Russo M, Russo GL. Autophagy inducers in cancer. Biochem Pharmacol. 2018 Jul;153:51-61. doi: 10.1016/j.bcp.2018.02.007. Epub 2018 Feb 10. PMID: 29438677.

36. Chung C, Seo W, Silwal P, Jo EK. Crosstalks between inflammasome and autophagy in cancer. J Hematol Oncol. 2020 Jul 23;13(1):100. doi: 10.1186/s13045-020-00936-9. PMID: 32703253; PMCID: PMC7376907.

37. Yao Y, Chen R, Wang G, Zhang Y, Liu F. Exosomes derived from mesenchymal stem cells reverse EMT via TGF- $\beta 1 /$ Smad pathway and promote repair of damaged endometrium. Stem Cell Res Ther. 2019 Jul 29;10(1):225. doi: 10.1186/s13287-019-1332-8. PMID: 31358049; PMCID: PMC6664513.

38. Song L, Chen TY, Zhao XJ, Xu Q, Jiao RQ, Li JM, Kong LD. Pterostilbene prevents hepatocyte epithelial-mesenchymal transition in fructose-induced liver fibrosis through suppressing miR34a/Sirt1/p53 and TGF-B1/Smads signalling. Br J Pharmacol. 2019 Jun;176(11):1619-1634. doi: 10.1111/bph.14573. Epub 2019 Apr 24. PMID: 30632134; PMCID: PMC6514378

39. Wang X, Lai Q, He J, Li Q, Ding J, Lan Z, Gu C, Yan Q, Fang Y, Zhao X, Liu S. LncRNA SNHG6 promotes proliferation, invasion and migration in colorectal cancer cells by activating TGF- $\beta /$ Smad signaling pathway via targeting UPF1 and inducing EMT via regulation of ZEB1. Int J Med Sci. 2019 Jan 1;16(1):51-59. doi: 10.7150/ijms.27359. PMID: 30662328; PMCID: PMC6332483.

\section{Figures}




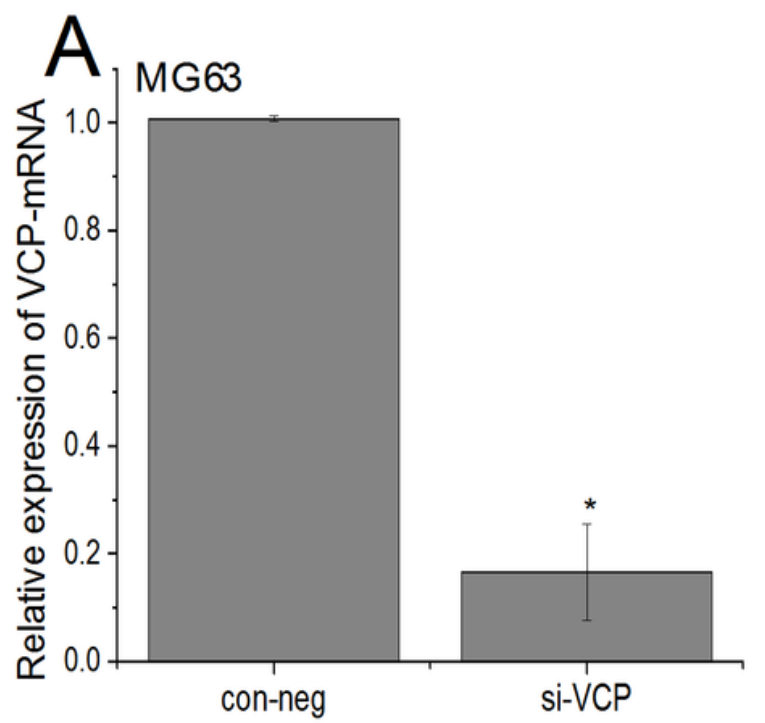

C

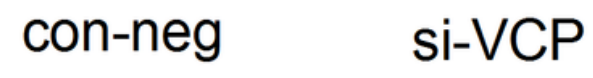

VCP

GAPDH

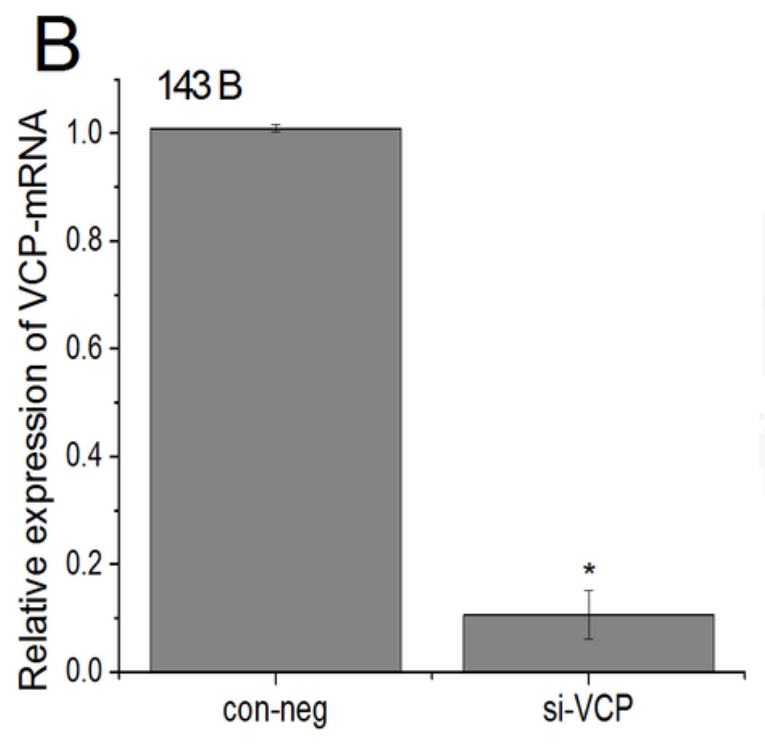

\section{MG63}

D

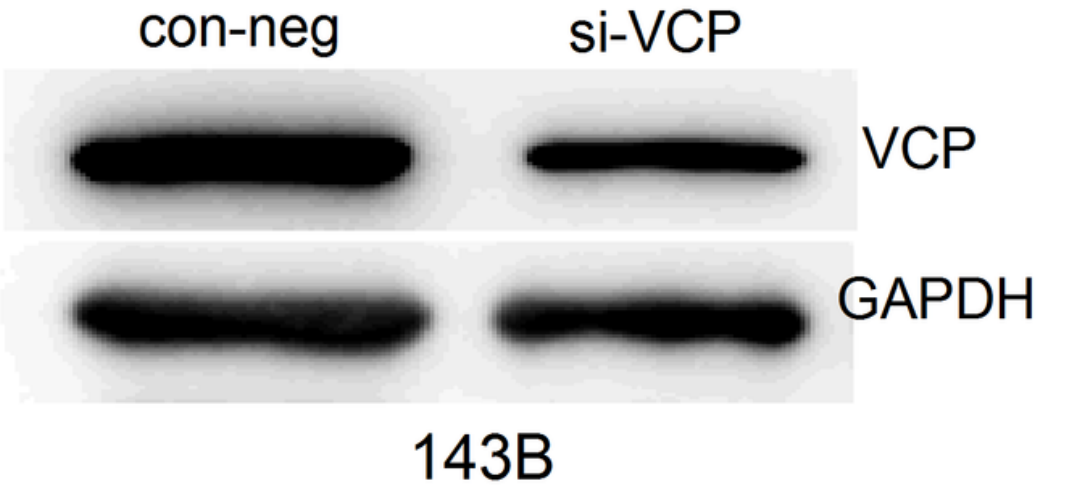

Figure 1

Legend not included with this version 


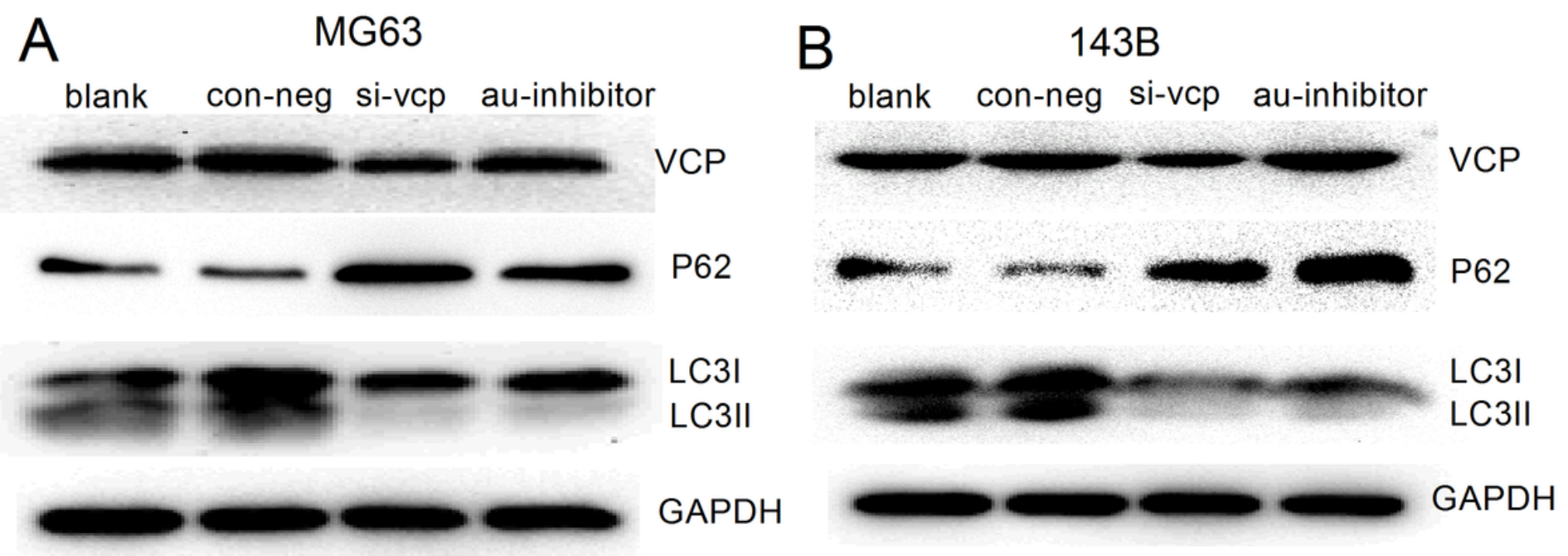

Figure 2

Legend not included with this version

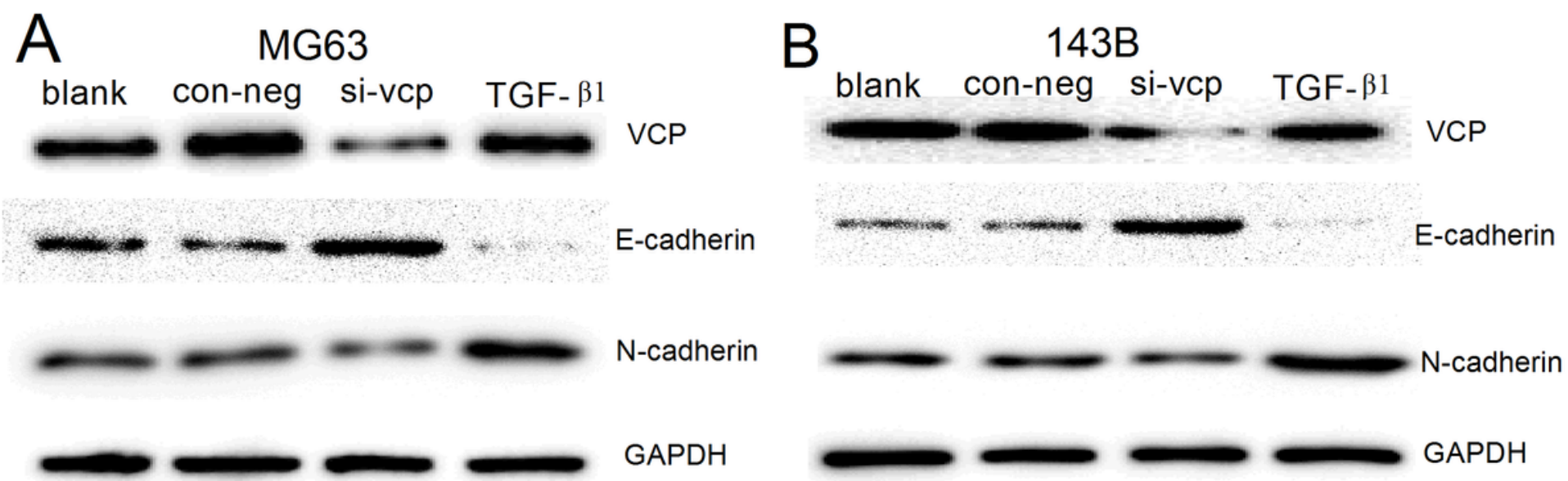

Figure 3

Legend not included with this version 

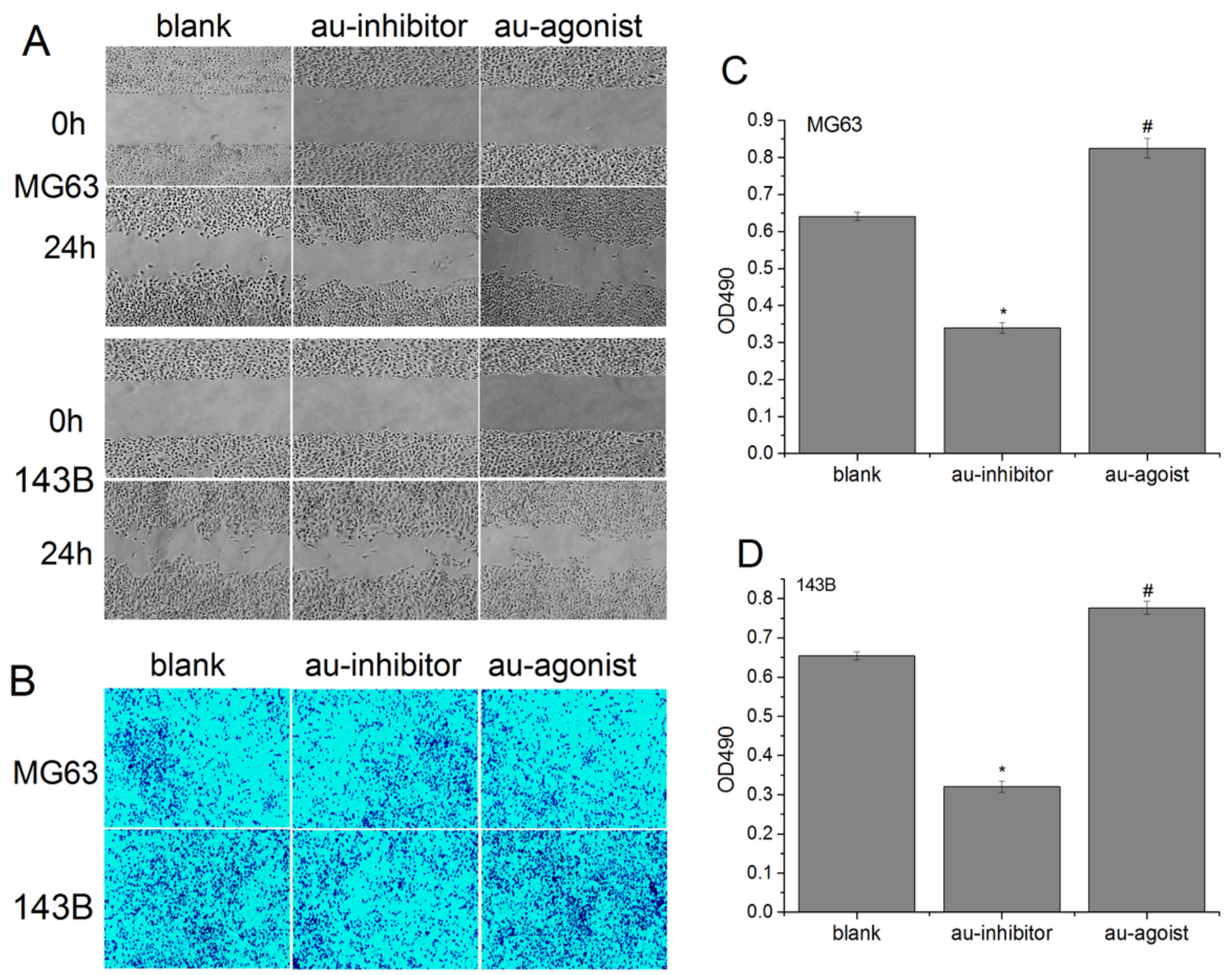

Figure 4

Legend not included with this version 


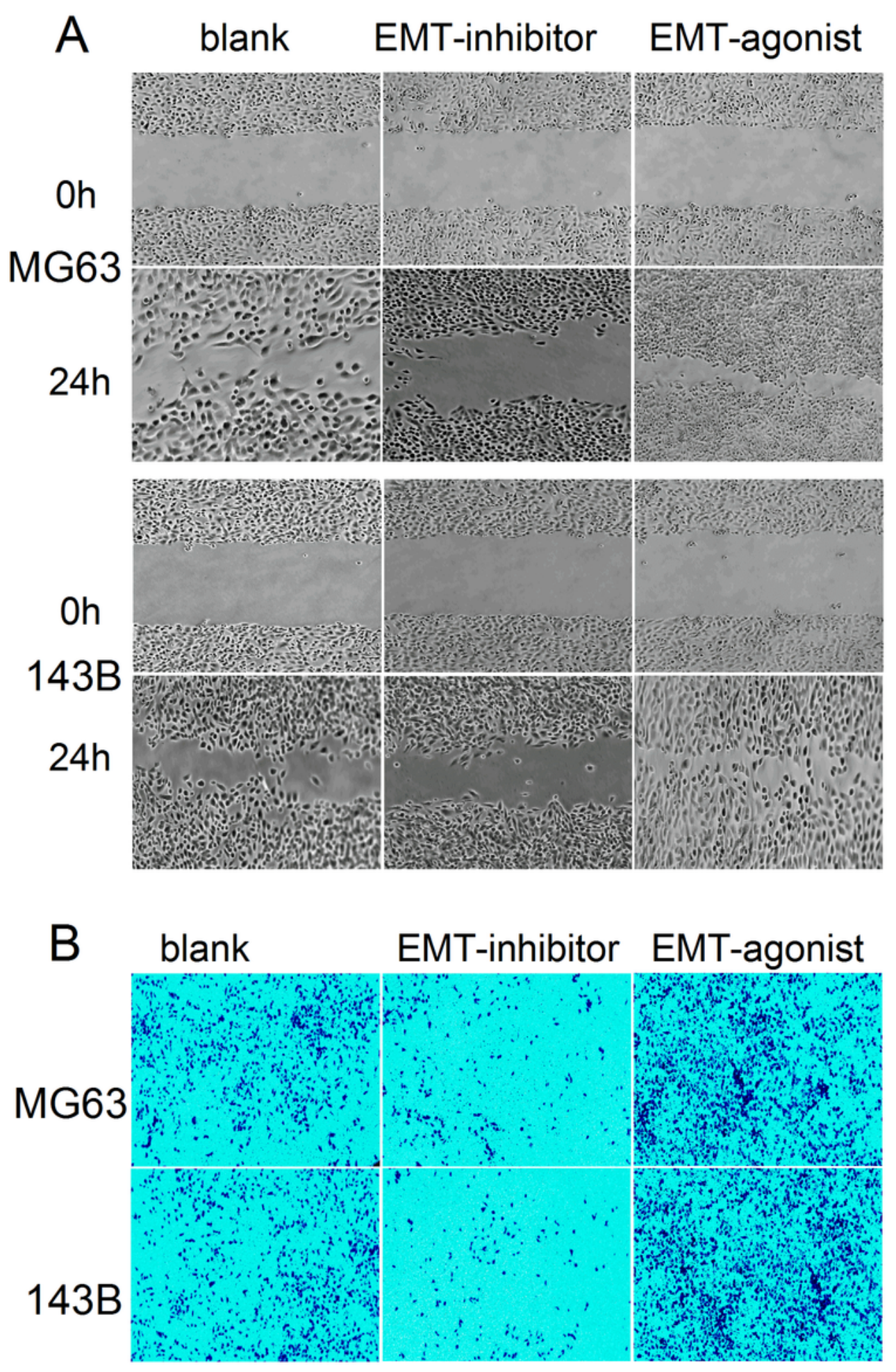

Figure 5

Legend not included with this version 


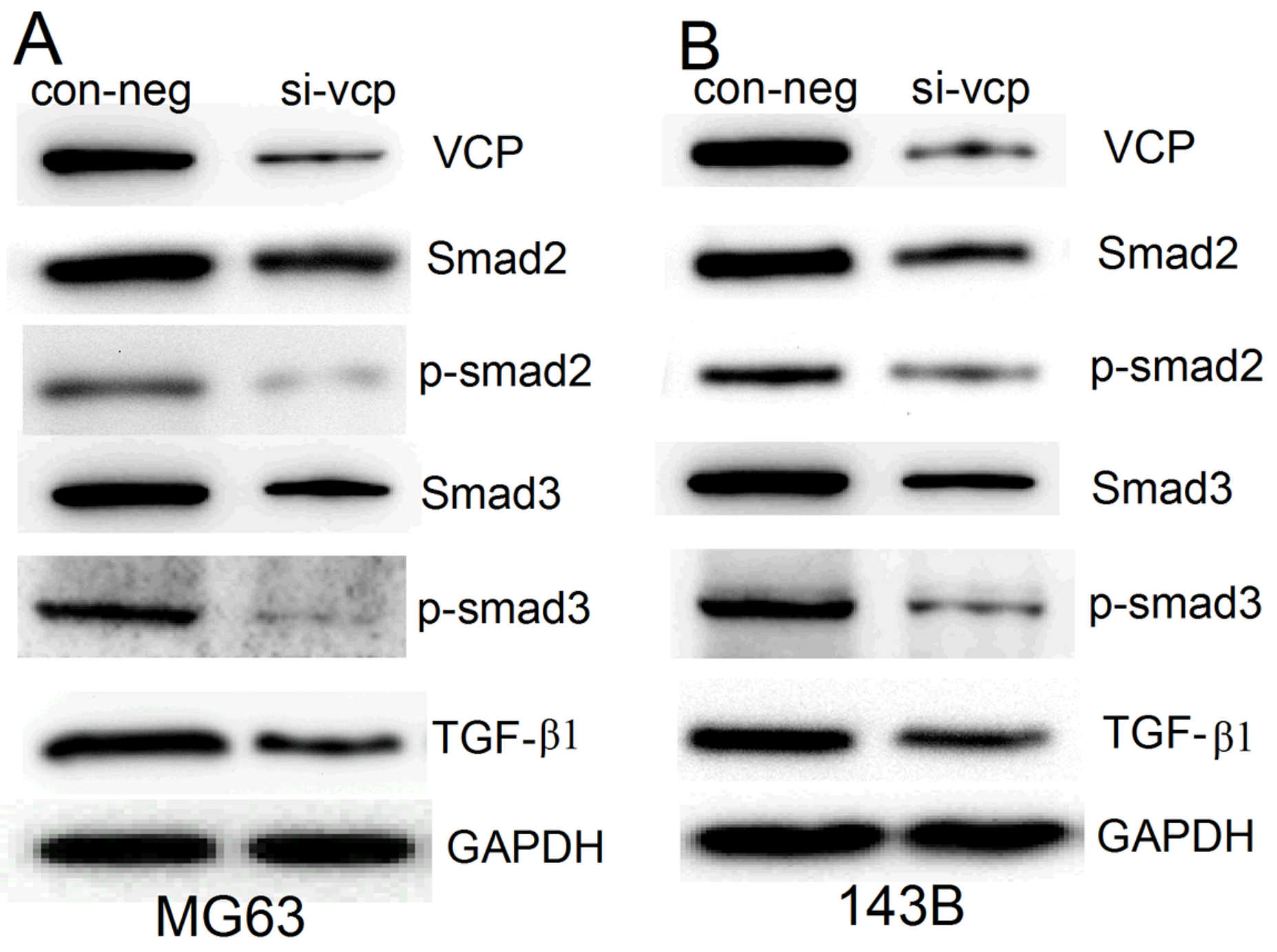

Figure 6

Legend not included with this version 